\title{
HIV/AIDS: Current Updates on the Disease, Treatment and Prevention
}

\author{
Praveen Kumar Gupta ${ }^{1} \cdot$ Apoorva Saxena $^{1}$ (i)
}

Received: 5 November 2019/Revised: 8 January 2021/Accepted: 19 January 2021/Published online: 23 April 2021

(C) The National Academy of Sciences, India 2021

\begin{abstract}
CCR5-delta 32 homozygous stem cell transplantation for HIV-infected individuals is being treated as a milestone in the global AIDS epidemic. Since 2008, when the second Berlin patient was cured from HIV after undergoing transplantation from a donor with delta-32 mutation, scientists are aiming for a long-term cure for the wider population. In 2019, a London patient became the second person to be free of HIV and came off the antiretroviral drugs completely. CCR5 gene is now being treated as a viable target for HIV treatment. It can be used in the treatment of HIV either through administration of drugs that bind to CCR5 and stop the receptor from working or through gene therapy to alter the CCR5 gene using CRISPR/Cas9 and prevent protein production. This review article aims to identify the obstacles and the need to overcome them in order to bridge the gap between current research and future potential cures for HIV.
\end{abstract}

Keywords CCR5-delta 32 - Homozygous · AIDS · HIV - Berlin patient · London patient · Drugs . CRISPR/Cas9

Significance Statement This article aims to increase awareness among the society about the current scenario of HIV/AIDS. The scientists are working on 2 types of cures-functional and sterilizing. The path to finding a cure is a promising one as late-phase trials begin in 2020 .

Praveen Kumar Gupta

praveenkgupta@rvce.edu.in

Apoorva Saxena

apoorvasaxena.bt17@rvce.edu.in

1 Department of Biotechnology, R.V College of Engineering, Bangalore 560059, India

\section{Introduction}

Human immunodeficiency virus or HIV is the cause of HIV infection that leads to the autoimmune disorder acquired immune deficiency syndrome (AIDS) [1] (Fig. 1). The major cause of spreading of HIV is through unprotected sex, during pregnancy from mother to foetus, through contaminated hypodermic needles and infected blood transfusions [1]. In the year 2016, an estimated 37 million people were living with HIV and 1 million deaths were reported. HIV/AIDS is a pandemic condition-an epidemic of diseases that spreads across large areas like multiple continents or even worldwide [1]. The first time AIDS was recognized was in the year 1981 by the United States Center for Disease Control and Prevention (CDC). Since the reported case of an individual who had successfully undergone a stem cell transplant from a person who showed a homozygous CCR5-delta 32 mutation, after receiving extensive high dose chemotherapy, there has been a greater interest in finding a potential cure.

\section{Virology}

HIV is a type of retrovirus that adversely infects the immune system of a human, mainly targeting the $\mathrm{CD} 4^{+}$ T-helper cells, accessory cells and the macrophages [2]. When it gains entry into the target cell, the viral genomic RNA undergoes a process of the reverse transcription with the help of reverse transcriptase enzyme and forms double stranded DNA (ds-DNA). This ds-DNA then gets integrated into the target cellular DNA with the help of enzyme integrase and other host co-factors [3]. The virus now can either become dormant or conceal itself and the target cell detection by the host immune system or it can get transcribed into new viral RNA and proteins that are released 


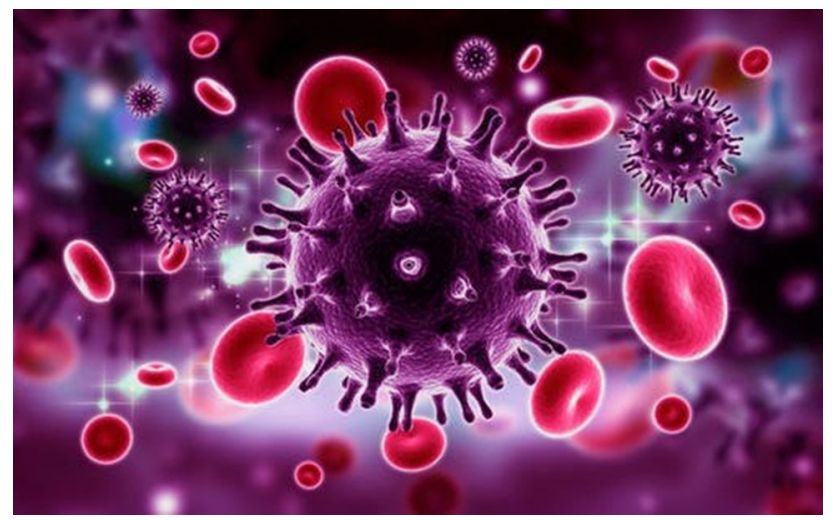

Fig. 1 Human Immunodeficiency Virus [5]

from the cell and begin the cycle again. HIV can be characterized into 2 major classes-HIV-1 and HIV-2. HIV-1, which is more virulent, infective and the major cause of HIV in humans, was discovered first and was initially referred to as HTLV-III or LAV [4] (Fig. 2). HIV2 is less infective and far fewer people exposed to it are infected.

\section{Mechanism}

The crucial factor in gaining entry into target cell is through binding of HIV to the CD4 receptor present on the T-helper cells and to one of the chemokine receptors- either CCR5 or CXCR4 [6, 7]. Binding to the co-receptor depends on the virus's tropism which is the ability to bind to a specific receptor. Naturally, there are two types of tropic strains-R5 that bind to CCR5 and X4 which bind to CXCR4. Dual tropic strains are capable of binding to both. Of these two co-receptors, CCR5 is the prime receptor for virus's entry into the target cell. R5-tropic strains prevail during early stages of infection, whereas the X4-tropic strains emerge later with disease progression. The envelope-like glycoprotein structure of HIV-1 is paramount in ensuring the viral entry into a target host cell [7]. This glycoprotein has 2 protein subunits: the gp41 (transmembrane) subunit and gp120 (external) subunit, which mimics a chemokine $[6,7]$. It does not manifest the unique structure of the chemokine but somehow manages to bind to both the co-receptors [6]. It forms a heterotrimeric complex wherein the gp120 subunit binds to the CD4 protein and specific co-receptor present on the target cell [6]. When this complex is formed, it triggers the release of a peptide which facilitates cell-cell fusion, that causes the viral membrane to fuse with the target cell membrane [6]. Binding to CD4 alone is not sufficient as it can result in gp120 shedding. So, it has to bind to the specific co-receptor for the fusion to proceed. The V1-V2 region of gp120 is recognized by the co-receptor, that influences which co-receptor will bind to the protein and is determined by degree of N-linked glycosylation and peptide composition. The highly variable V3 loop is the one that determines co-receptor specificity. The binding of gp120 glycoprotein to the CCR5 co-receptor is determined by two essential factors - the tyrosine-sulphated amino terminus of CCR5 receptor and following which there must be reciprocal action between the transmembrane domains of CCR5 and gp120 protein, i.e., inter-communication and synergy.

\section{Antiretroviral Therapy}

The usage of a combination of three or more antiretroviral drugs for suppression of the HIV infection is called

Fig. 2 Structure of HIV-1 [8]

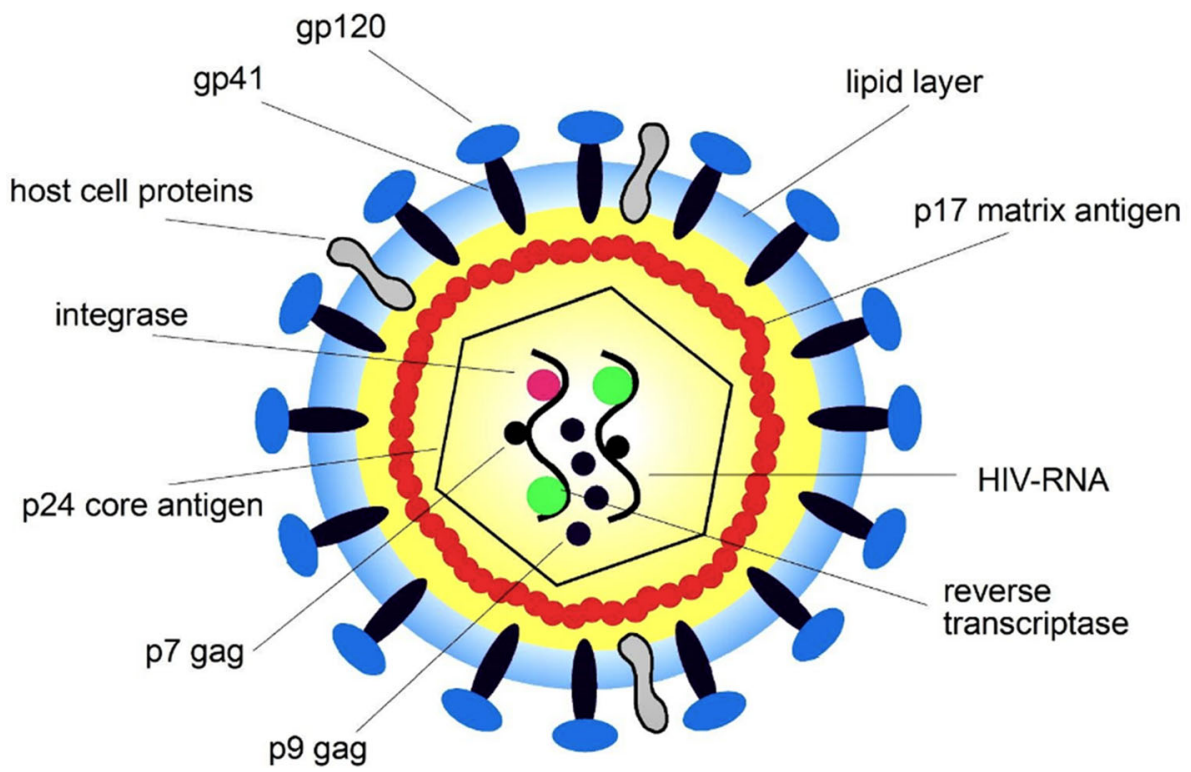


antiretroviral therapy. Using multiple drugs in combination to increase the effectivity on various viral targets is called highly active antiretroviral therapy (HAART). It helps in maintaining the immune system to function, preventing HIV from developing resistance and other infections that potentially lead to death. The five classes of drugs used in combination to treat HIV infection are: entry inhibitors, nucleoside/nucleotide reverse transcriptase inhibitors, nonnucleoside reverse transcriptase inhibitors, integrase inhibitors and protease inhibitors.

\section{Zidovudine}

Zidovudine/ZVD (also called azidothymidine) is an extensively used antiretroviral medication [9]. It is a thymidine analogue and is dosed twice daily in combination with other antiretrovirals. Its function is to particularly inhibit the reverse transcriptase enzyme which is necessary for the production of ds-DNA.

Cellular enzymes are used in converting AZT into the 5 'triphosphate form. Research studies suggest that the termination of forming ds-DNA chains is a crucial factor that leads to an inhibitory effect.

Studies have also shown that at very high dosage of this drug, its triphosphate form may inhibit the DNA polymerase enzyme which is used for cell division by the uninfected cells and mitochondria for replication. It may lead to toxic but reversible effects on certain skeletal and the cardiac muscles, causing the condition of myositis [10]. However, zidovudine also shows greater affinity for the reverse transcriptase enzyme, which is around 100-fold. This selectivity has been

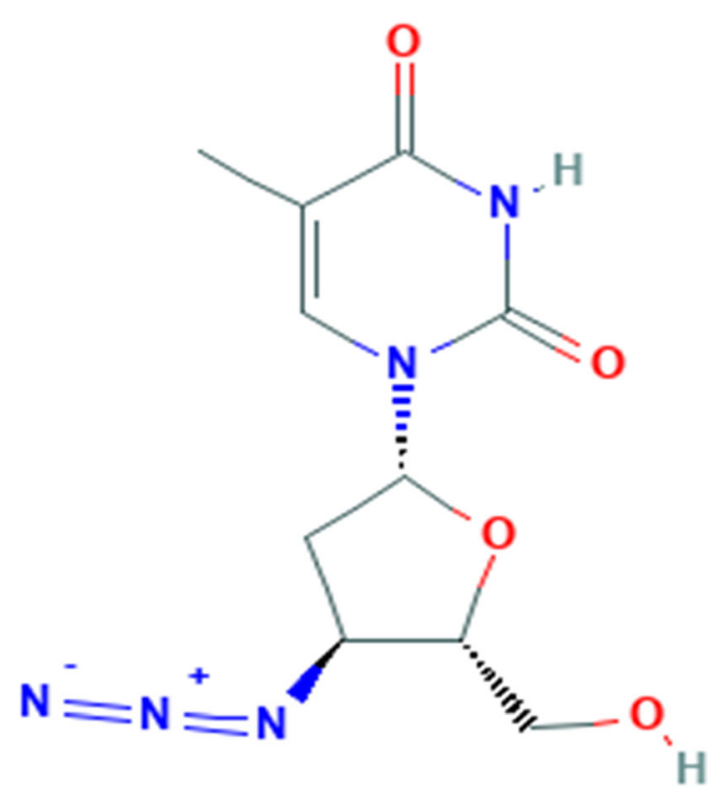

Fig. 3 Structure of zidovudine [11] proven by the cell's ability to quickly repair its DNA strands if broken by AZT during its formation, whereas the HIV virus will lack this ability (Fig. 3).

Zidovudine is commonly used in combination with nucleotide reverse transcriptase inhibitor, non-nucleoside reverse transcriptase inhibitor, HIV integrase strand transfer inhibitor and protease inhibitor [9]. The combination of lamivudine and zidovudine is not recommended for nonpregnant HIV-infected adults and adolescents due to greater toxicity but is used as an alternative, though not a preferred one, in antiretroviral-naive pregnant women as an initial treatment [9]. However, for paediatric patients (neonates, infants and children of age 12 or less), zidovudine with lamivudine/emtricitabine is a preferred option. For adolescents greater than the age of 12 , it is an alternative [9].

\section{Zidovudine Administration and Pharmacokinetics}

\section{Administration and Dosage}

It is usually administered orally or by continuous IV infusion, although not rapid infusion and IM injection [9] (Tables 1,2). The dosage for paediatric patients and adult patients depends on their body weight (Tables 3,4).

\section{Administration}

Zidovudine: $1 \mathrm{mg} / \mathrm{kg}$ every $4 \mathrm{~h}$ [9].

\section{Pharmacokinetics}

Pharmacokinetics gives a detailed view of the fate of drugs in the human system. It includes various components like absorption, distribution, excretion or elimination and metabolism (Tables 5, 6, 7). The stability of such retroviral drugs should also be taken into account for both oral and parenteral dosage forms (Table 8).

\section{Contraindications [9]}

- Zidovudine has a history of life-threatening hypersensitivity reactions like Stevens-Johnson syndrome and anaphylaxis to the drug or maybe due to some ingredient in the formulation.

- Lamivudine/zidovudine: hypersensitivity history.

- Abacavir/zidovudine/lamivudine: history of hypersensitivity to abacavir, zidovudine or lamivudine; hepatic impairments may be mild or severe. 
Table 1 Oral administration [9]

\begin{tabular}{|c|c|c|}
\hline Type of administration & Type of combination used & $\begin{array}{l}\text { Strictly prohibited in patients with following } \\
\text { conditions }\end{array}$ \\
\hline Tablets, capsules and oral solution irrespective of meals & $\begin{array}{l}\text { Zidovudine/lamivudine- } \\
\text { Oral, } 2 \text { times daily, irrespective } \\
\text { of meals }\end{array}$ & $\begin{array}{l}\text { Paediatric patients weighing }<30 \mathrm{~kg} \\
\text { With renal disorders }-\mathrm{Cl}_{\mathrm{cr}}<50 \mathrm{ml} / \mathrm{min} \\
\text { With hepatic disorders } \\
\text { Experiencing dose-limiting effects that may } \\
\text { be adverse }\end{array}$ \\
\hline $\begin{array}{l}\text { Oral solutions for children who are not able to swallow } \\
\text { capsules and tablets }\end{array}$ & $\begin{array}{l}\text { Lamivudine/Abacavir/ } \\
\text { Zidovudine- } \\
\text { Oral, } 2 \text { times daily, irrespective } \\
\text { of meals }\end{array}$ & $\begin{array}{l}\text { Paediatric patients weighing less than } 40 \mathrm{~kg} \\
\text { With renal disorders }-\mathrm{Cl}_{\mathrm{cr}}<50 \mathrm{ml} / \mathrm{min} \\
\text { With hepatic disorders - moderate or severe }\end{array}$ \\
\hline
\end{tabular}

Table 2 IV administration [9]

\begin{tabular}{|c|c|c|c|}
\hline \multicolumn{2}{|l|}{ Dilution } & \multicolumn{2}{|c|}{ Rate of administration } \\
\hline \multirow{3}{*}{\multicolumn{2}{|c|}{$\begin{array}{l}\text { Zidovudine concentrate- }-10 \mathrm{mg} / \mathrm{ml} \text { dilution before administration } \\
\text { Withdraw appropriate dose and dilute in } 5 \% \text { dextrose injection to } \\
\text { make a solution of concentration less than or equal to } 4 \mathrm{mg} / \mathrm{ml}\end{array}$}} & \multicolumn{2}{|c|}{ Infuse over $60 \mathrm{~min}$ - in adults it is given intermittently } \\
\hline & & \multicolumn{2}{|c|}{ Infuse over $30 \mathrm{~min}$-intermittently given in neonates } \\
\hline & & \multicolumn{2}{|c|}{$\begin{array}{l}\text { Pregnant HIV-infected women (prophylaxis regimen): give initial dose of } \\
\text { over } 60 \mathrm{~min} \text {, then by continuous infusion at a rate of } 1 \mathrm{mg} / \mathrm{kg} \text { per hour }\end{array}$} \\
\hline Body Weight (kg) & \multicolumn{2}{|c|}{ Dosage regimen (2 times daily) } & Dosage regimen (3 times daily) \\
\hline $4-9$ & \multicolumn{2}{|l|}{$12 \mathrm{mg} / \mathrm{kg}$} & $8 \mathrm{mg} / \mathrm{kg}$ \\
\hline $9-30$ & \multicolumn{2}{|l|}{$9 \mathrm{mg} / \mathrm{kg}$} & $6 \mathrm{mg} / \mathrm{kg}$ \\
\hline$\geq 30$ & \multicolumn{2}{|l|}{$300 \mathrm{mg}$} & $200 \mathrm{mg}$ \\
\hline
\end{tabular}

Table 4 Dosage for adult patients [9]

\begin{tabular}{llll}
\hline Body weight $(\mathrm{kg})$ & Type of combination & Dosage regimen & No. of tablets \\
\hline No restriction & Zidovudine & $200 \mathrm{mg}$ thrice daily/300 mg twice daily & 1 \\
$\geq 30$ & Zidovudine/lamivudine & Lamivudine: $150 \mathrm{mg}$ & $1-$ twice daily \\
& & Zidovudine: $300 \mathrm{mg}$ & Abacavir: $300 \mathrm{mg}$ \\
$\geq 40$ & Lamivudine/abacavir/zidovudine & Zidovudine: $300 \mathrm{mg}$ & twice daily \\
& & Lamivudine: $150 \mathrm{mg}$ \\
\hline
\end{tabular}

\section{CCR5 Gene}

\section{CCR5 Gene Structure}

$\mathrm{C}-\mathrm{C}$ chemokine receptor type 5 (also called CCR5 or CD195) is a receptor for chemokines present on the white blood cells. The CCR5 gene in humans is located on the short arm (p) at position 21 on chromosome number 3
(Fig. 4). It is mainly expressed cells like T-cells, macrophages, microglia, dendritic cells and eosinophils and is found within a cluster of genes coding for some other receptors like XCR1, CCBP2, etc. [12, 13]. The gene has two promoters, three exons and two introns. Pu or PR2, the upstream promoter, has a $1.9 \mathrm{~kb}$ region, $57 \mathrm{bp}$ in length and precedes the exon 1 [12]. Exon 1, which is the start of the coding region, is followed by the first intron, $501 \mathrm{bp}$ in 
Table 5 Absorption [9]

\begin{tabular}{|c|c|c|}
\hline Bioavailability & Food & Special populations \\
\hline $\begin{array}{l}\text { Mean bioavailability is approx. } 64 \% \text {., gets well-absorbed, plasma } \\
\text { concentrations (peak) within } 0.5-1.5 \mathrm{~h} \\
\text { AUC is same for both ZVD tablets, oral solution and capsules } \\
\text { One tablet containing lamivudine- } 150 \mathrm{mg} \text { and zidovudine- } 300 \mathrm{mg} \text { is } \\
\text { bioequivalent to one tablet each of lamivudine and zidovudine of same } \\
\text { dosages } \\
\text { One tablet containing lamivudine- }-150 \mathrm{mg} \text {, abacavir- } 300 \mathrm{mg} \text { and } \\
\text { zidovudine- } 300 \mathrm{mg} \text { s bioequivalent to one tablet each of all three with } \\
\text { same dosages }\end{array}$ & $\begin{array}{l}\text { Absorption (AUC) is } \\
\text { independent of } \\
\text { meals }\end{array}$ & $\begin{array}{l}\text { Patients with renal impairments-AUC } \\
\text { increases } \\
\text { Bioavailability in infants }(61 \%) \text {, in neonates } \\
(89 \%) \text { and in paediatric patients }(65 \%) \\
\text { Pharmacokinetics of zidovudine is same for } \\
\text { both pregnant and non-pregnant women }\end{array}$ \\
\hline
\end{tabular}

Table 6 Distribution [9]

\begin{tabular}{|c|c|c|c|}
\hline \multicolumn{3}{|l|}{ Extent } & $\begin{array}{l}\text { Plasma protein } \\
\text { binding }\end{array}$ \\
\hline $\begin{array}{l}\text { Distributed widely in the human body } \\
\text { In the CSF, with ratio of CSF/plasma cor } \\
\text { In semen, milk, crosses the placenta and } \\
\text { tissues, liver }\end{array}$ & $\begin{array}{l}\text { c. of } 0.15 \text { to } 2.1 \\
\text { gets distributed into cord blood, amni }\end{array}$ & iotic fluid, foetal blood and & iver, CNS \\
\hline Metabolism pathway & Route of elimination & Half-life period & Special population \\
\hline $\begin{array}{l}\text { Metabolized through glucuronidation in } \\
\text { the liver } \\
\text { Intracellularly, ZVD is phosphorylated, } \\
\text { converted to the active } 5^{\prime} \text {-triphosphate } \\
\text { which is a metabolite }\end{array}$ & $\begin{array}{l}\text { Eliminated principally in urine via } \\
\text { both glomerular filtration and } \\
\text { tubular secretion } \\
\text { ZVD cannot be removed by } \\
\text { haemodialysis or peritoneal } \\
\text { dialysis }\end{array}$ & $\begin{array}{l}\text { In adults it is } 0.5-3 \mathrm{~h} \\
3.1 \mathrm{~h} \text { in neonates, } 1.9 \mathrm{~h} \text { in } \\
\text { infants and } 1.5 \mathrm{~h} \text { in } \\
\text { paediatric patients }\end{array}$ & $\begin{array}{l}\text { Patients with hepatic impairments: } \\
\text { ZVD clearance is decreased. } \\
\text { Half-life of } 1.8 \mathrm{~h} \\
\text { Patients with severe renal } \\
\text { impairments: Half-life of } 1.4 \mathrm{~h}\end{array}$ \\
\hline
\end{tabular}

Table 8 Stability of antiretrovirals [9]

\begin{tabular}{lcll}
\hline Oral & Parenteral & & \\
\hline Capsules & Solution & Tablets & Concentrate for IV fusion \\
$\begin{array}{c}\text { Protection from light, } \\
\text { heat and moisture }\end{array}$ & $25{ }^{\circ} \mathrm{C}$ to & Zidovudine: $20{ }^{\circ} \mathrm{C}$ to & Protection from light \\
Storage: $15{ }^{\circ} \mathrm{C}$ to & & $25{ }^{\circ} \mathrm{C}$ & Storage: $15{ }^{\circ} \mathrm{C}$ to $25{ }^{\circ} \mathrm{C}$ \\
$25{ }^{\circ} \mathrm{C}$ & & Lamivudine/ & When diluted in $5 \%$ dextrose: physically and chemically stable for $24 \mathrm{~h}$ at room \\
& & Zidovudine: $2{ }^{\circ} \mathrm{C}$ to & temperature and $48 \mathrm{~h}$ when refrigerated at $2{ }^{\circ} \mathrm{C}$ to $8{ }^{\circ} \mathrm{C}$ \\
& $30{ }^{\circ} \mathrm{C}$ & Diluted solutions should be administered within $8 \mathrm{~h}($ at room temperature) and \\
& Abacavir/Zidovudine / & $24 \mathrm{~h}$ (refrigerated) so as to curtail risk of microbial contamination \\
& Lamivudine: $2{ }^{\circ} \mathrm{C}$ & \\
\hline
\end{tabular}

length. The second exon 2 is intron-less. It is found as exon $2 \mathrm{a}, 235 \mathrm{bp}$ in length, and exon $2 \mathrm{~b}, 54 \mathrm{bp}$ in length. Pd or PR1, the second promoter, accommodates the intron 1 and exon 2 regions [12]. A $1.9 \mathrm{~kb}$ length intron is located between exon 2 and exon 3 . Exon 3 is also intron-less and consists of the full ORF of the CCR5 gene, $11 \mathrm{bp}$ of the $5^{\prime}$ untranslated regions and the complete $3^{\prime}$ untranslated regions [12].

These two promoters are devoid of the consensus TATA and CCAAT sequences, although the Pd promoter has a 


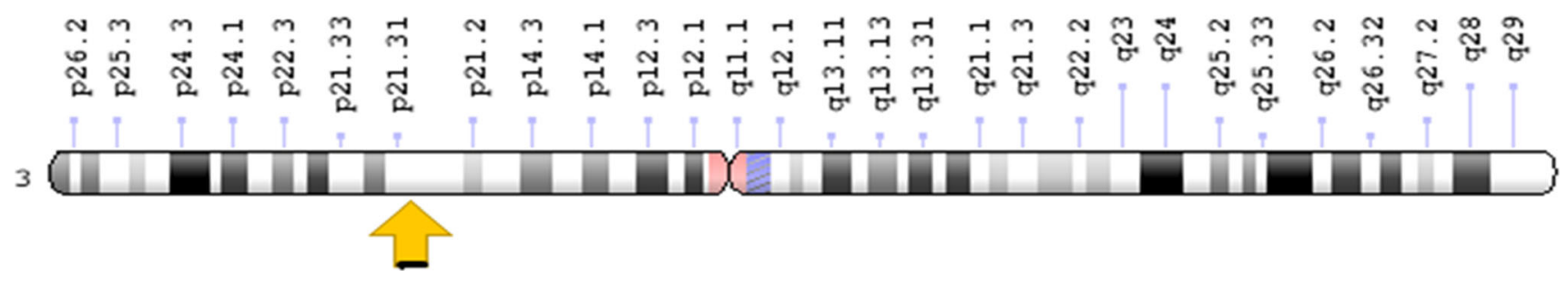

Fig. 4 Location of CCR5 gene on chromosome 21 [14]

non-consensus TATA sequence and have an unusually high content of pyrimidine in them [12]. The upstream $\mathrm{Pu}$ promoter was found to be weaker than the downstream Pd promoter which had exhibited up to fivefold greater activity. But these results were established as erroneous [13]. With the help of RT-PCR technique, it was later identified that the $\mathrm{Pu}$ promoter was used in stimulated T-cells and the Pd promoter was used in unstimulated primary T-cells [13]. The error resulted due to the use of transformed T-cells affecting the overall expression of CCR5 protein via the $\mathrm{Pu}$ promoter [13]. Results also showed that transcription of the CCR5 gene when controlled by the $\mathrm{Pu}$ promoter containing exon 1 resulted in CCR5A or B and when controlled by the Pd promoter resulted in truncated isoforms [13].

\section{CCR5 Gene Expression Regulation}

The expression of CCR5 gene is regulated at three levels: 1. genetic factors, 2 . factors involved in activation, signalling and trafficking of the receptor which includes desensitization, internalization and recycling and 3. environmental triggers [13].

CCR5 receptor is part of the G-protein coupled receptor family, which binds to its ligand and releases $\alpha \mathrm{i}$ and $\beta \gamma$ G-protein subunits. This results in a mediated effector response. Such responses stimulate the release of phospholipase $C \beta$ and adenylyl cyclase. This in turn facilitates the release of intracellular calcium and form inositol triphosphate [13]. This leads to activation of phosphorylation of the CCR5 receptor which occurs at the serine and $\mathrm{C}$-terminal residues via protein kinase $\mathrm{C}$ and $\mathrm{G}$-protein coupled receptor kinases [13]. The regulatory proteins, $\beta$ arrestin 1 and 2, bind to the activated serine and the conserved DRY motif in the intracellular loop [13]. The $\beta$ arrestin proteins have functions like desensitizing the receptor to further stimulation and participating in endocytosis. The CCR5 expression level is controlled by the rates of recycling and endocytosis [13]. In the endocytosis process, $\beta$-arrestin protein facilitates the binding process between clathrin-coated pits and the phosphorylated receptor. Infection and entry of HIV into cells do not require CCR5 signalling, but the chemokine-induced endocytosis decreases the available receptor for HIV entry. This is the process of chemokine-mediated anti-HIV activity [13].

Environmental factors affecting CCR5 expression are infectious pathogenic agents like Mycobacterium tuberculosis, which increases the CCR5 expression. Studies have shown that CCR5 expression is considerably increased in all leukocyte subset cells during tuberculosis and dual infection with HIV [13]. However, the level of CCR5 expression on $\mathrm{CD}^{+}{ }^{+}$T-cells was not increased. Conversely, it was also shown that HIV affects the level of expression of CCR5, due to a correlation with HIV disease progression. Individuals with end stage HIV were shown to have the highest percentages of CCR5 expressing CD4 ${ }^{+}$ T-cells [13].

The regulation of CCR5 is complex. The introns as well as sequences in the $5^{\prime}$ UTR and $3^{\prime}$ UTR affect CCR5 gene regulation [13]. Therefore, mutations in these regions should be considered critical in the regulation process.

\section{CCR5-Delta 32 Mutation}

The discovery of CCR5-delta 32 mutation in the CCR5 gene in 1996 which exhibited some protection against HIV was a ground breaking one. Studies showed that the $\mathrm{CD} 4^{+}$ T-cells when expressing this mutation prevented HIV envelope fusion [12] (Fig. 5). The mutant allele has a length of 215 in comparison to the wild type which contains 352 amino acid residues [13]. This mutation basically results due to the deletion of 32 base pairs from the position of nucleotides starting from 794 till 825, a frameshift mutation, and seven new amino acids are incorporated between amino acid 174 and stop codon at amino acid 182 [13] (Fig. 6). This mutation affects the region of second extracellular loop where the resultant protein lacked the last three transmembrane domains and also some regions necessary for G-protein interaction and signal transduction.

This mutation is majorly restricted to people of European descent. The gene frequencies are found to be around $10 \%$ and shows a decline from north to south latitude. A 2-5\% gene frequency in Europe, the Middle East and parts of the Indian subcontinent was observed in more than 3000 individuals. The highest frequency, at $20.93 \%$, was 


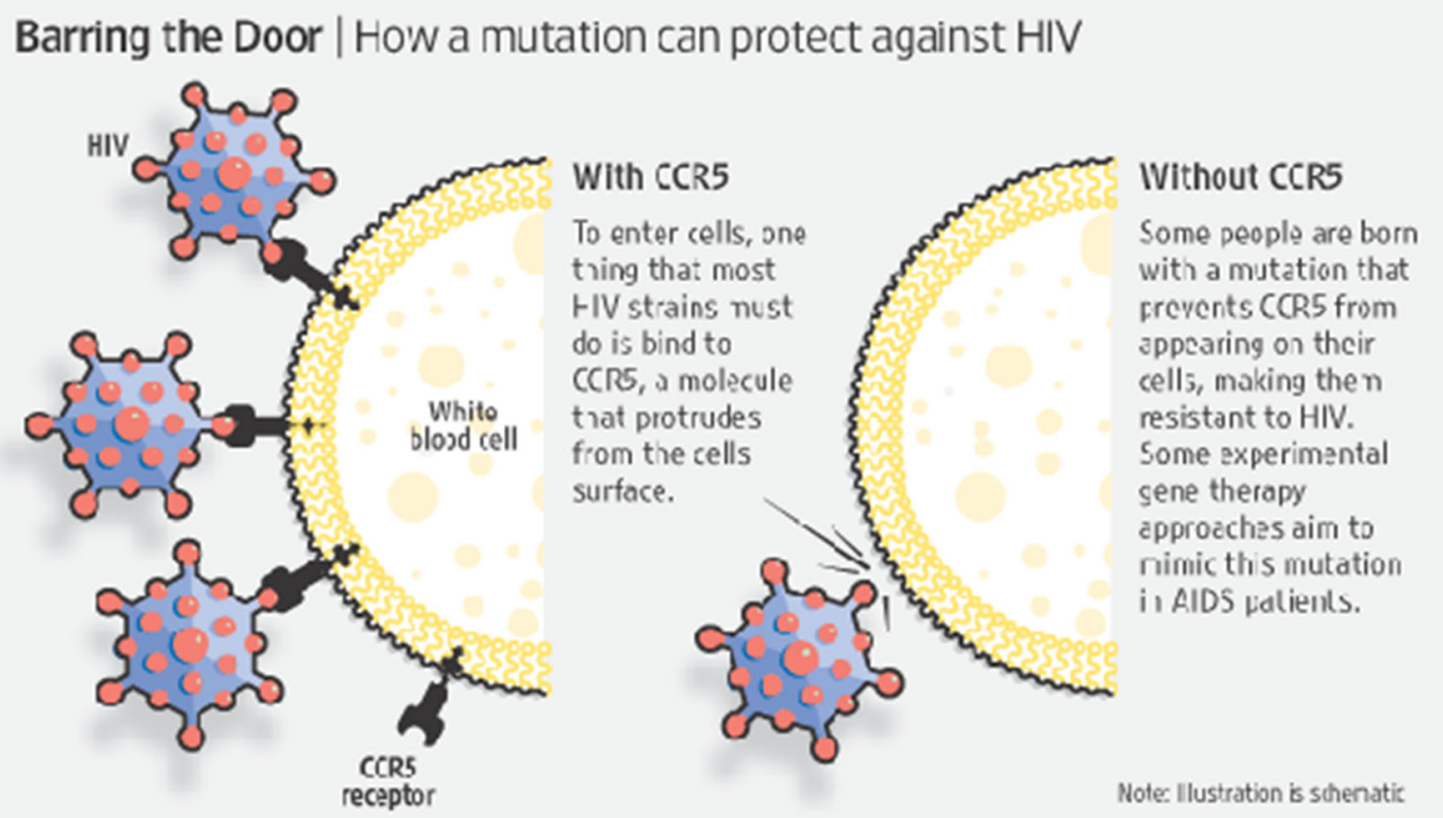

Fig. 5 Comparison of HIV infecting cell with CCR5 and without CCR5 [15]

\section{CCR5}

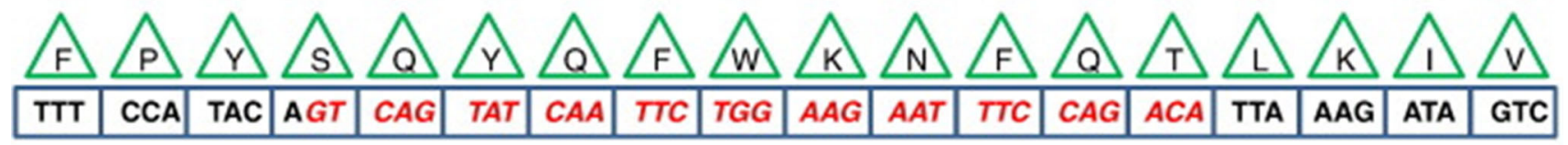

\begin{tabular}{|l|l|l|l|l|l|l|l|l|l|l|}
\hline TTT & CCA & TAC & ATT & AAA & GAT & AGT & CAT & CTT & GGG & stop \\
\hline
\end{tabular}

\section{CCR5 $\Delta 32$}

Fig. 6 Difference between wild type CCR5 and CCR5-delta 32 [16]

discovered in the Ashkenazi Jewish population. The mutant allele is absent in Black populations excluding the African American group who may have acquired the mutation through genetic admixture [13].

The origin of the delta-32 mutant allele has been dated back to the year 275-1875, which increased over a period of time as a result of selective pressure, mainly the Black plague. However, historical data have shown that Black plague may not in fact be the cause [13]. The distribution of the delta-32 mutant allele in a north to south gradient does not correlate to the casualties of the plague and instead follows a south to the north gradient. The Black plague has shown the greatest casualties in areas like the Mediterranean region and China, with lowest allele frequencies of the mutation [13].
Studies suggested that delta-32 arose without a selective event. Tandem repeats found in the coding region of the CCR5 gene could cause unequal homologous recombination, which results in the delta-32 allele. The origins of the delta-32 mutation, however, remain a mystery [13].

The hype about the delta-32 mutation comes from its ability to protect homozygous individuals from HIV. The protective effect of the delta-32 mutation is a result of eliminating the expression of CCR5 protein on the cell surface, which prevents HIV's entry into the cell. In the year 1997, however, studies showed that some of them having the homozygous delta-32 mutation were HIV-infected [13]. Further studies revealed the HIV virus was of the $\mathrm{X} 4$ type, which led to very rapid $\mathrm{CD} 4^{+} \mathrm{T}$ cell decline. Hence, this mutation is limited in its function and does not 
protect against viral strains which utilize other receptors or show dual-tropism [13].

In contrast, however, the delta-32 protein product which is localized to the endoplasmic reticulum is an important factor. It is shown to exert a trans-dominant negative effect on the wild-type CCR5 protein, which inhibits its transport to the cell surface. Further analysis in vitro showed the reduction of surface expression of wild type CCR5 and CXCR4 through dimerization by this mutant protein product [13]. This confers an inhibition to R5, X4 and R5X4 HIV infections [13]. Homozygous delta-32 individuals with this mutant protein were shown to have suppressed CXCR4 surface protein expression and decreased susceptibility to X4 infection. Experimental proofs also suggested that delta-32 heterozygous individuals with HIV infection do not stably express the mutant protein, are devoid of the molecular mechanism of complete protection and only maybe partially protected [13].

\section{Stem Cell Transplantation}

Stem cells are undifferentiated cells that can differentiate into specialized cells and can also undergo mitosis to produce more stem cells. There are mainly two classesembryonic stem cells (ECS) and adult stem cells. Stem cells are also taken from the umbilical cord blood just after birth. These act as a repair mechanism for the body, such as skin, blood or intestinal tissues. Adult stem cells are majorly used in medical therapies like bone marrow transplantation. Bone marrow is the spongy tissue present inside the bones which serves as a rich source of adult stem cells. Long-term control of HIV is possible with CCR5delta 32 stem cell transplantation [13].

Allogeneic transplantation of stem cells with this mutation in patients with HIV infection and malignancy has been considered as an option since the late 1990s (Fig. 7). Human leukocyte antigen (HLA) is a critical factor to be considered during the process of transplantation. The HLA should be a proper match; otherwise, it would lead to rejection by the recipient's immune system. The limited availability of HLA-matched unrelated donors has made it even more difficult. Only about $1 \%$ of Caucasians possess this CCR5 null allele [13].

\section{Gene Therapy}

Zinc finger nuclease technology is a popular tool which can be used for targeting specific DNA sequences in the genome. It falls in the class of restriction enzymes and is artificially made by fusing a zinc finger DNA-binding domain and DNA-cleavage domain. This technique is also engineered to eliminate the CCR5 expression over CD4 ${ }^{+}$ T-cells, and the modified cells have shown to have a half- life of 48 weeks [13]. But it has its own issues. It is difficult to ensure that the desired repair mechanism is one which is used to repair the double stranded break (DBS) [13]. It is also challenging to scale it upwards and is an expensive technique.

A breakthrough technique, the CRISPR/Cas9 geneediting system, is also used to eliminate the CCR5 receptor on the blood stem cells which can give rise to differentiated blood cells that are devoid of this receptor [18] (Fig. 8). These gene-edited stem cells can be established into an HIV-infected patient through bone marrow transplantation and give rise to an HIV-resistant immune system [18]. This technique, however, can also go sideways which leads to unwanted results that can cause ethical issues to rise. As seen in the highly controversial case of the Chinese scientist, He Jiankui, who with the help of this technology deleted the CCR5 gene in the twins, Lulu and Nana, introduced some unintended mutations in their genetic codes. There is still a lot of research needed to make this technology bioethically a safe tool.

Researchers have also engineered a molecule called the chimeric antigen receptor (CAR) and introduced a gene for that molecule into blood-forming stem cells [18]. This molecule has two receptors that will recognize the antigen (HIV) and direct the immune cells to locate and kill the HIV-infected cells [18]. When transplanted into mice, which would have the CAR-carrying blood stem cells, it would result in reduced levels of HIV by inducing the immune cells to fight effectively against the virus [18]. An $80 \%$ to $95 \%$ drop in viral load was observed in the mice [18]. It was concluded that gene therapy could be a feasible option for treatment in HIV-positive humans.

\section{Immunological Approaches}

Studies have shown that vaccine can contribute effectively in viral clearance such as the Rhesus CMV vaccine vector [18]. A vaccine vector is a kind of vaccine which consists of chemically weakened viruses that are transported in the body to generate an immune response. The genes used in these vaccines are antigen coding surface proteins from that particular pathogen.

SAV001-H is the first and only preventive HIV vaccine which uses killed HIV-1 virus [18]. It is unique from other vaccines, as it uses genetically engineered whole virus genome, eliminating its pathogenicity and inactivating its virulence through irradiation and chemical treatments, finally approaching to the first "whole-killed virus"-based HIV vaccine [18]. The results of Phase 1 clinical trial, which were completed in the year 2013, were found to have serious and adverse effects in the 33 participants [18]. There was also a surprising boost in the antibody production against p24 and gp120. The HIV viral core is mostly 


\section{Allogeneic bone marrow transplant}
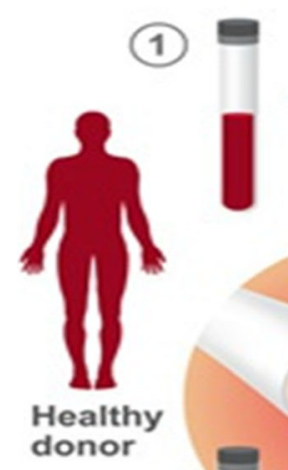

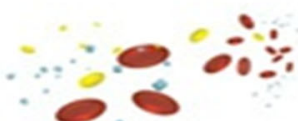

Stem cells are taken with blood

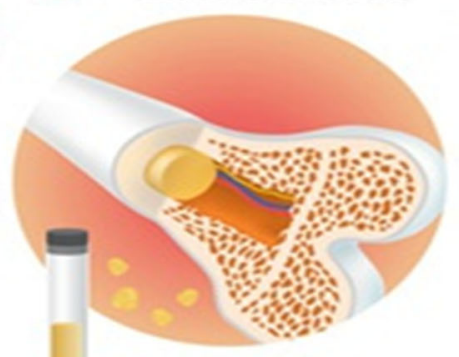

Stem cells are taken with bone marrow

(6)
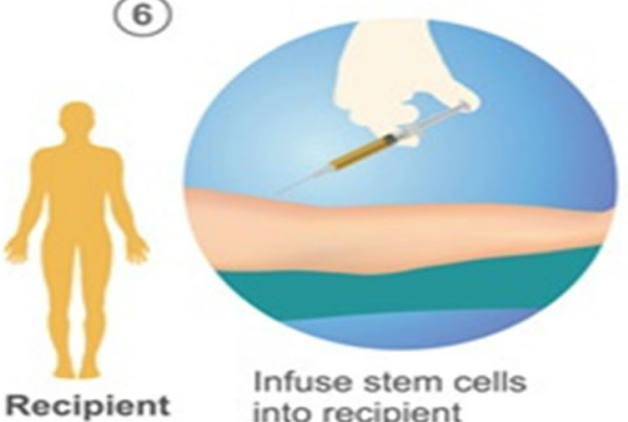

Infuse stem cells into recipient
(2)

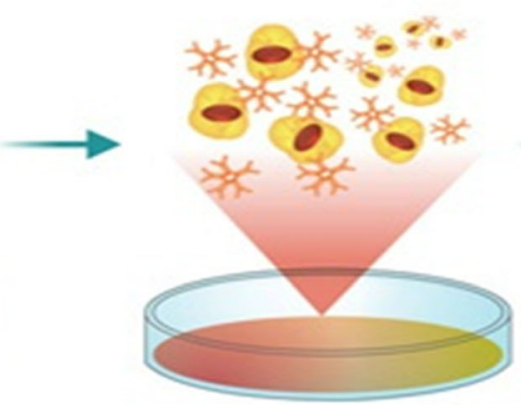

Stem cells are separated out and incubated with antibodies

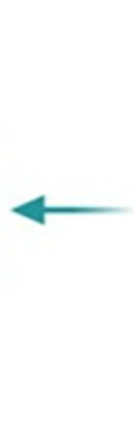

Dilute stem cells
(3)

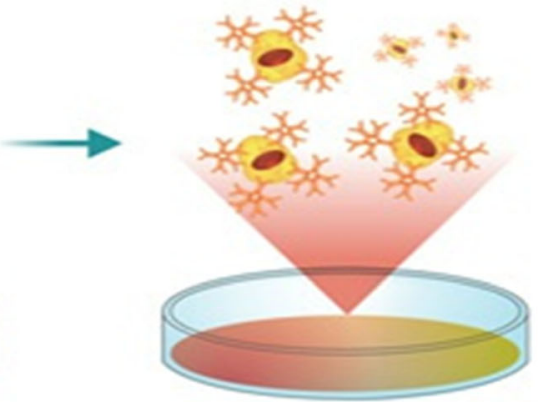

Stem cells that bind with antibodies are selected

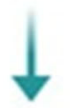

(4)

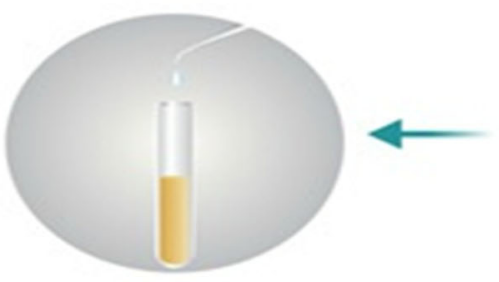

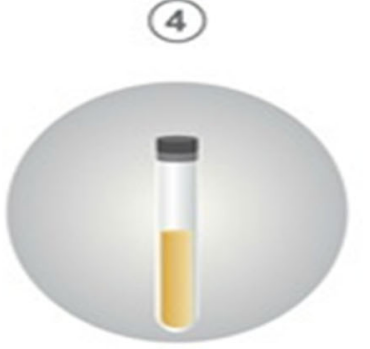

Reduce volume of fluid with stem cells

\section{Recipient : (low Immunity system, chemotherapy or radiation therapy)}

Fig. 7 Allogeneic hematopoietic stem cell transplant [17]

made up of the structural protein, p24, which is called the capsid. A crucial factor in the diagnosis of primary HIVinfected individuals is the p24 antigen assay. High levels of p24 are found in the blood serum during the period between infection and seroconversion. The antibody production is found to increase as much as 64-fold [18]. The antibody production against gp120, which is a glycoprotein, necessary for attachment to a cell receptor and allow HIV entry, is found to increase up to eight-fold [18].

Another promising vaccine called the Kang's vaccine also uses the "whole-killed HIV-1," which is similar to vaccines developed for rabies, polio and influenza [18]. However, HIV-1 is genetically engineered in such vaccines and raises questions about safety and possibility of large quantity production.

Researchers have also tested an immunogen called eODGT8 60mer, a protein nanoparticle, which is designed to mimic a crucial part of the HIV envelope protein which will bind to and activate the B cells to produce plasma cells that secrete antibodies needed to fight HIV [18]. This nanoparticle was developed in the Schief laboratory and tested in mouse models engineered by the Nemazee laboratory [18]. The researchers showed that immunization with eOD-GT8 60mer produced antibody progenitors with some of the characters crucial to recognize and block the HIV infection, proposing that it could be a promising first step in a series of immunizations against HIV [18]. The vaccine appears to work well in mouse models. The researchers are now investigating other immunogens that could work in coexistence with eOD-GT8 60mer [18]. 


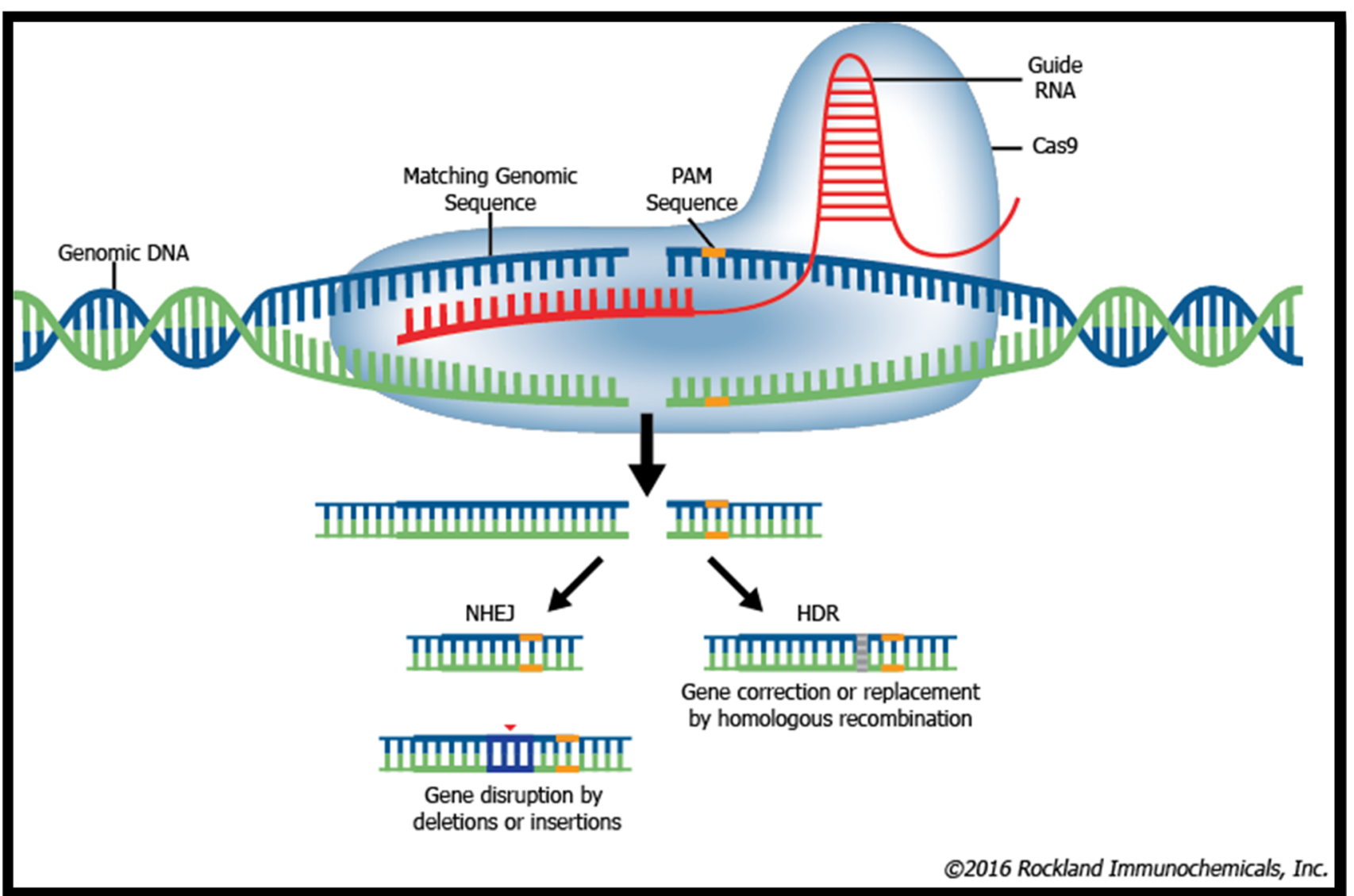

Fig. 8 CRISPR/Cas9 gene editing [19]

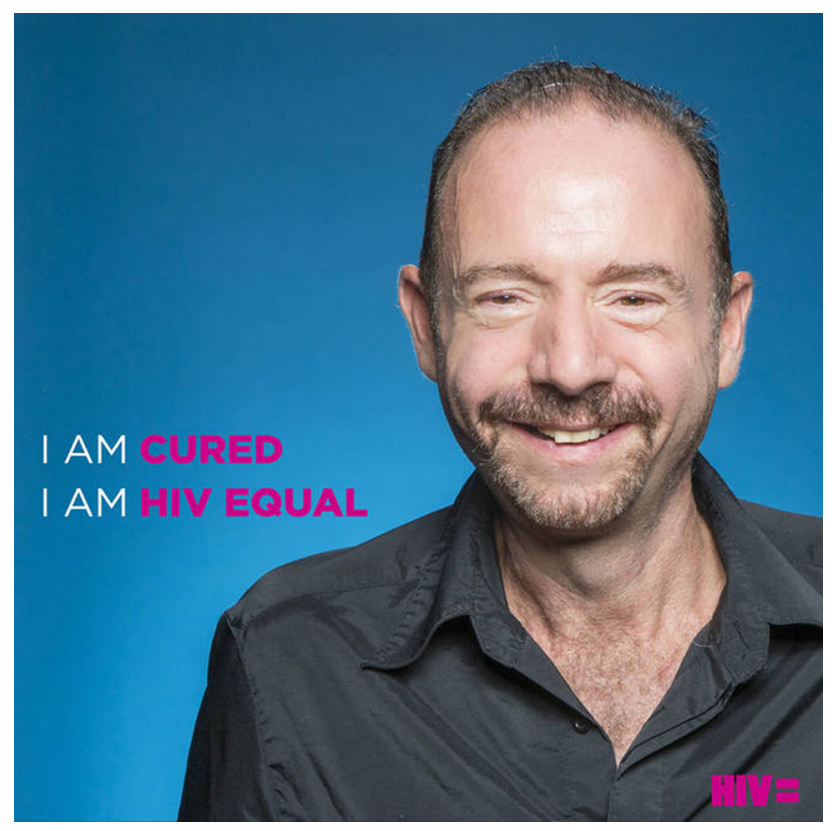

Fig. 9 Timothy Ray Brown a.k.a. "The Berlin patient" [21]

\section{Case Studies}

\section{The Berlin Patient [20]}

The strongest proof available in favour of a HIV cure stems from the case of Timothy Brown who is popularly known as the Berlin patient (Fig. 9). He is considered the first person ever to be cured of HIV. The victory was predicated on doctors taking advantage of nature's own experimentthe genetic mutation of CCR5 gene that produces a protein co-receptor present on the surface of $\mathrm{CD}^{+}{ }^{+} \mathrm{T}$-cells that HIV uses to gain entry. He was attending university in Berlin when was diagnosed HIV positive. His initial treatment include ART, and he was taking low doses of zidovudine and protease inhibitors. He continued to live a normal life for the next 10 years. But one day, he was again feeling extremely exhausted and the doctor had diagnosed it to be anaemia. He had received red blood cell transfusion for nearly a week and was then sent to an oncologist, Dr Huetter, when the previous doctor was unable to resolve the situation. The oncologist performed a painful bone marrow biopsy and after further diagnosis he was informed that he had acute myeloid leukaemia (AML). 
He then started receiving treatment at one of the Berlin University hospitals and had to receive four rounds of chemotherapy treatment. During the third round of chemotherapy, he had gotten a fatally dangerous infection and was immediately put into an induced coma. His blood sample was collected and sent to a stem cell donor bank with the German Red Cross to find matches in case he needed transplantation. Luckily, he had 267 matches which sparked an idea to locate donors with a homozygous CCR5 delta-32 mutation on $\mathrm{CD}^{+}{ }^{+}$T-cells who are almost immune to HIV infection. A donor was found at the $61 \mathrm{st}$ attempt and had agreed to donate when necessary (Fig. 10).

However, Timothy Brown had been reluctant and had said no to transplantation as the success rate was only 50-50. But at the end of 2006, leukaemia had rebounded and he desperately needed transplantation to survive. He received the stem cell transplant on February 6, 2007 and stopped taking his antiretroviral medication. Nearly 3 months after he underwent transplantation, HIV was no longer found in his body and he had thrived until the end of the year.

Unfortunately, life had other plans for him. After coming back from a trip to the USA, he was diagnosed with pneumonia and the leukaemia was back. The doctors decided to treat him with a second transplantation from the same donor in February 2008. The recovery was a tough one. He was almost paralyzed and went nearly blind. He had, however, eventually learnt to walk again and fully recovered 6 years later. He was continuously tested for HIV with extensive and precise tests. It was finally good news for him! Since 2010, when he decided to go public, he had interviewed for various magazines: POZ Magazine, New York Magazine and Science Magazine among others and decided to devote his life in supporting research for cures against HIV. In July 2012, he started the Timothy Ray Brown Foundation under World AIDS Institute and has worked with many scientists, organizations, research laboratories and universities to work on cures such as vaccination against HIV.

\section{The London Patient [22]}

The London patient may be the second person with HIV to no longer have the virus. In March 2019, in a report published in journal Nature, a group of investigators had announced the cure of a second HIV-positive patient. His success story depicts that CCR5 is a viable target for HIV research and treatment.

The London patient, who had chosen to remain anonymous, came out in public on March $9^{\text {th }} 2020$. Adam Castillejo grew up in Caracas, Venezuela, and later shifted to London with his mother, as his parents were divorced. He was first diagnosed with HIV in 2003 and had started taking drugs to control the HIV infection in 2012. He had taken antiretroviral therapy for years before being diagnosed with an advanced form of blood cancer called Hodgkin's lymphoma. Again, as in the case of the Berlin patient, the cancer was resistant to standard chemotherapy, so his doctors had advised more intensive chemotherapy along with bone marrow stem cell transplant. In 2016, he had agreed to transplantation and received it from a healthy donor who carried the CCR5 mutation. So, when his immune system regrew, it lacked the protein and was impervious to HIV. His virologist, Dr Ravindra Gupta, from the University of Cambridge, thinks it is a cure because a year had passed and they had carried out a few more tests for the viral load. In Adam Castillejo's own words, "I don't want people to think, "Oh, you've been chosen." No, it just happened. I was in the right place, probably at the time right time, when it happened." Adam Castillejo wants to be the "ambassador of hope" for people with this illness.
Fig. 10 Adam Castillejo a.k.a "The London patient" [23]

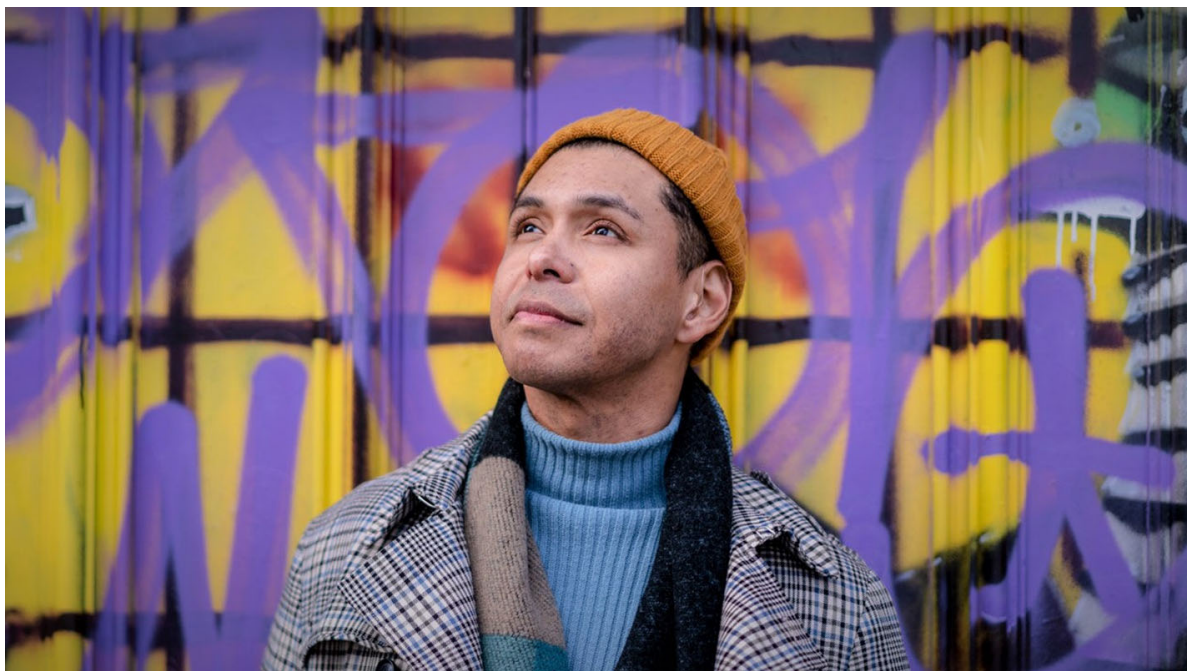


Table 9 Summary of the two cases - the Berlin patient and the London patient [24]

\begin{tabular}{lll}
\hline Parameters & The Berlin patient (Timothy Ray Brown) & The London patient (Adam Castillejo) \\
\hline Type of HIV Virus & HIV-1 Positive & HIV-1 Positive \\
Antiretroviral therapy received & Yes & Yes \\
Type of cancer & Blood Cancer (Acute myeloid leukaemia) & Blood Cancer (Hodgkin's lymphoma) \\
Received Chemotherapy & Yes & Yes \\
Received bone marrow stem cell transplant & Yes & Yes \\
Type of donor & Homozygous for CCR5-d32 mutation & Homozygous for CCR5-d32 mutation \\
Absence of virus in blood after ART & Yes & Yes \\
$\quad$ termination and transplantation & & Mild \\
Graft-versus-host disease & Mild & Post-transplantation: hematopoietic stem cells \\
Status of full donor chimerism & Post-transplantation: hematopoietic stem cells & found to be of donor origin \\
Conditioning regimen- mild/invasive & found to be of donor origin & Mild \\
No. of times transplant was performed & 2 & 1 \\
\hline
\end{tabular}

Although the scientists describe this case as a long-term remission, experts are calling it a potential cure. Such transplants are, however, dangerous and can be fatal. They are also an impractical approach to cure the millions already infected. These are highly risky procedures and can lead to serious complications. There still has to be a lot of research done to extend this type of treatment to a wider population infected with HIV.

A comparative study of the two patients reveals that their cases were in fact quite similar (Table 9).

\section{Lifestyle Practices to Prevent HIV Infection}

Prevention is better than cure. And with HIV infections, one should practice prevention with utmost care and sincerity. An HIV diagnosis could turn one's life upside down. So, it's better to lead a healthy lifestyle by making the correct choices.

\section{Measures for Protection Against HIV Infection}

HIV is majorly spread through unprotected vaginal or anal sex. Choose less risky behaviour and be cautious. Not taking medicines to prevent or treat HIV is equally responsible for HIV infection. The number of sexual partners should be limited. One should get tested for sexually transmitted diseases and also know the sexual partner's status. One can talk about pre-exposure prophylaxis to their respective healthcare provider. It is a preventive option for people who are not infected yet but are exposed to high risks of being HIV positive. HIV is also spread through intravenous injections and blood transfusions. Use of sterile equipment in such cases is a necessity.

\section{Pre-exposure Prophylaxis}

This is a preventive method of taking pills by people who are not HIV positive yet but who are at a high risk of getting infected and spreading it to others. A pill, named Truvada, contains two medicinal components, emtricitabine and tenofovir, that are used in combination with other drugs to treat HIV [25]. These medicines work on keeping the virus from creating a permanent infection.

\section{Post-exposure Prophylaxis}

Post-exposure prophylaxis (PEP) is a short course of HIV medicines taken soon after a possible exposure to HIV [25]. Every hour counts. For the treatment to be effective, the course should begin within $72 \mathrm{~h}$ after exposure to HIV; otherwise, it will not have any effect [25]. This treatment should be used only in cases of emergency. A person prescribed with PEP will need to take the medicines for 28 days at a stretch and then visit their respective healthcare provider for further tests [25]. Even if taken correctly, it may not be $100 \%$ effective. The sooner the medication is started, the better.

\section{Healthy Practices to Follow When Living with HIV}

A healthy, well-balanced and nutritious diet can help a person lead a better life by preventing health related issues like malnutrition and stopping the progression from HIV to AIDS. A well-balance diet is rich in whole grains, fresh fruits and vegetables, protein, low fat dairy products and multivitamins like zinc and B12. It also constitutes what should be cut down-fried foods, processed foods and sugary drinks. Smoking should be stopped when diagnosed 
with HIV. According to CDC, in the USA, the rate of adults with HIV, smoking is two to three times higher in adults infected with HIV than the nearly $18 \%$ of uninfected adults who smoke. Researchers at the Syracuse University analysed the data from 212 adults infected with HIV and found that the ones who smoked reported having more symptoms like dizziness and coughing.

Putting a stop to illegal drug use is equally necessary. People should seek treatment for addiction to illegal drugs like heroin, cocaine and methamphetamines. Sharing of needles for drugs can leave one exposed to other infections like hepatitis which might lead to a faster progression from HIV to AIDS. A recent study from the University of Pennsylvania School of Medicine showed a dramatic increase in the ability of HIV to attack healthy cells when methamphetamine is present in the bloodstream. This indicates that illegal drugs are also aiding in the HIV infection.

Being physically fit through a good work-out three to six times a week can help improve a person's mood, perspective and overall quality of life. A good amount of moderate exercise can help fight HIV symptoms of nerve pain, loss of appetite and reduce the risks of other chronic diseases like heart disease, diabetes and osteoporosis. Taking the prescribed medication on time is known as adherence. This is vital to help reduce the risk of HIV becoming drug resistant and helps the immune system function for a longer time.

Nowadays, with the help of Internet of Things or IoT, patient's health can be monitored 24/7. The quality of care provided can be increased many-folds with the help of monitoring devices enabled with current technology [26]. Concept of E-Health and M-Health is currently trending. E-Health makes use of electronic and communication processes with improved cyber security [26]. Some of the E-Health devices include GPS tracking, pedometer and electronic health records [26]. M-Health systems provide doctors with the complete medical history of the patient, so the treatment becomes easier and does not delay in case of emergencies. It makes use of mobile phones and other communication systems to help the patients with information about preventive health care services and collects data in real time as well [26]. The other important applications include chronic disease management, monitoring of diseases and tracking of epidemic outbreaks [26].

\section{Genomic Diversity and Clinical Implications}

Despite billions of dollars being invested, there is currently no HIV vaccine available that can either prevent the disease or treat those who suffer from it. An AIDS patient harbours 100 million genetically distinct variants of HIV
[27]. This high diversity of HIV-1 is due to high replication rates, errors in reverse transcriptase and recombination events that mainly occur during the viral replication process. Reverse transcriptase enzyme has approximately a rate of $10^{-4}$ nucleotide substitutions per replication cycle. Deletions, insertions and duplications are major contributing factors to the genetic variation of the virus [27]. Genetic recombination also plays an important role in creating genetic diversity. Template switches between two copies of RNA strands occur regularly during reverse transcription [27]. This generates a lot of mutations with the help of inter- and intra-molecular jumps. These mutations can either be drug resistant or inhibit the viral replication capacity.

HIV-1 can be classified into four main groups: $\mathrm{M}, \mathrm{N}, \mathrm{O}$ and the recently identified $\mathrm{P}$. The $\mathrm{M}$ group is further identified into 4 subtypes (A to J). Studies have shown that there is a worldwide spread of non-B subtype viruses, and with the introduction of antiretroviral drugs, more research has to be conducted regarding the responsiveness of the drug resistance in non-B subtypes [27]. Different types of HIV-1 resistance are observed in different subtypes at varied levels. For example, subtypes B and $\mathrm{G}$ have shown to develop resistance against nelfinavir [27]. Research is also being done in the role of polymorphisms for development of drug resistance, to assess the genotypes before and after the therapy to be able to establish any association between the two [27].

\section{Variation of Disease Progression Rate}

There are 3 phases of the progression of HIV-1 infectionprimary infection, chronic asymptomatic phase of infection and finally, AIDS. In the asymptomatic phase, neither signs nor symptoms of the disease are present, and this phase lasts an average of about 10 years. They can be divided as typical progressors, rapid progressors, slow progressors and long-term progressors. Rapid ones (10-20\%) develop AIDS within 5 years of infection [28]. Slow progressors (5-15\%) remain free of AIDS 15 years after infection [28]. Long-term progressors that constitute 1\% show no signs and symptoms [28]. Factors like host genetic make-up, immune responses, co-infection and viral genetics and adaptation are attribute to this huge variation in disease progression [28]. But there is no solid evidence as such.

Some individuals known as elite controllers are able to manage the viral replication for longer durations, others are shown to rapidly lose $\mathrm{CD} 4^{+} \mathrm{T}$-cells after seroconversion in the absence of cART (combination antiretroviral therapy). Scientists have conducted research studies that has led to the conclusion that rapid progression before administration of cART stops the recovery of $\mathrm{CD}^{+}{ }^{+} \mathrm{T}$-cells once the suppressive response to HIV-1 through cART is achieved. 
These findings have implications in public health policy making, clinical outcomes and science research. Ideally, cART should be initiated as soon the patient is diagnosed with HIV-1 irrespective of the CD4 ${ }^{+}$T-cell count. However, in clinical settings where cART is not widely available, these results would support strategies that may help in promoting frequent testing to reduce the proportion of patients initiating cART at low $\mathrm{CD} 4^{+} \mathrm{T}$-cell counts. For those testing early, frequent $\mathrm{CD} 4^{+} \mathrm{T}$-cell count should be monitored close to the time of HIV diagnoses to establish the rapid progressors phenotype in order to avoid unnecessary $\mathrm{CD} 4^{+} \mathrm{T}$-cell count decay among rapid progressors. Finally, interpretation of the immunopathological basis of rapid progression can help improve individual clinical outcomes and limit its impact in the global HIV-1 pandemic.

\section{Development of Drug Resistance as a Major Barrier to Treat HIV}

HIV-1 has a high mutation rate. An estimated $10^{10}$ virions per day can be produced in untreated patients that may result in variants called quasispecies. The complexity is also increased due to high recombination rate whenever more than one variant infects the same cell. All these are contributing factors that help in invading the host's immune system and fostering drug resistance. Salvage therapy is also useful in cases when more than one regimen failed or a single regimen failed for a patient. It can be used to suppress the virus levels below the detection level and should have high genetic barrier to resistance to prevent rebound [29]. Clinicians need to focus on patient's adherence as well as access to antiretrovirals (ARVs), drug interactions, tolerability, genotypic and phenotypic resistance testing, cross-resistance, genetic barrier and potency of ARVs [29].

\section{Overcoming Obstacles and Future Prospects}

At present, the reason for not being able to achieve a complete cure with the help of ART, in spite of achievement of undetectable viral load, is due to the presence of dormant virus or HIV latency. In a method call shock and kill, immune stimulants shock the latent virus from hidden reservoirs and then attempt to kill reactivated HIV [18]. An enzyme has been identified which is called histone deacetylase (HDAC) which is responsible for the sustained latency. Some studies show promise but are yet to be confirmed by clinical trials. Flushing these latent CD4 HIV-infected cells from their reservoirs with these HDACinhibitors into the blood circulation makes them susceptible to ART. Vorinostat and panobinostat are two such promising drugs [18].
Histone deacetylase inhibitors seem to have a broad spectrum of epigenetic activities. Vorinostat (also called Zolinza) is a U.S. Food and Drug Administration approved medicine, which has been used for the treatment of cutaneous T-cell lymphoma (CTCL) [18]. They help in flushing the virus from the reservoirs into the circulation. The dose is $400 \mathrm{mg}$. Other drugs on the pipeline are Protein kinase C agonist bryostatin-1 and GS-9620-TLR7 agonist [18].

Romidepsin (also called Istodax) is another HDAC inhibitor drug, which induces HIV-1 transcription to form plasma HIV-1 RNA that can be easily detected with standard assays [18]. This gives a possibility of reversing the HIV-1 latency in vivo without hindering $\mathrm{T}$ cell mediated immune response [18]. These findings will help the researchers with future clinical trials aiming to eliminate the HIV-1 reservoirs.

Research for curing HIV is at an infant stage but a promising one. Scientists are working on two broad types of HIV cures-a functional cure and a sterilising one.

The approach of the functional cure is to reduce the virus levels in the body to an undetectable stage, where the patient no longer needs to be on HIV medication or has no risk of progression to AIDS nor transferring the virus to others. Unlike the functional cure, however, a sterilising cure aims to get rid of HIV from the body completely by eliminating cells from latent reservoirs. It has proved to be an extremely challenging task for scientists, who believe it may be unachievable in the majority of them living with HIV. However, some findings by researchers at the University of Pittsburgh could lead to a foundation for an HIV vaccine. Clinical trials are in the works.

Abivax, a French company, is developing a drug that binds to some specific sequence of the viral RNA and inhibits its replication. During clinical trials, it has shown that this may have the potential to become a functional cure. The key is that it can target the reservoir of HIV viruses that hide inactive within our cells. It can target the reservoirs where HIV viruses act as inactive, within the infected cells. The result of phase IIa trial was quite promising. Fifteen patients were given the drug in combination with ART, and it was observed after 28 days of treatment that eight patients showed a $25 \%$ to almost $50 \%$ reduction of their HIV reservoirs compared to those only taking ART. The company is planning a phase IIb clinical trial to confirm the effects of the drug in the long term.

\section{Conclusion}

Research and development in HIV and its cure have come a long way since the disease was discovered in the 1980s. ART was a major milestone that has changed the lives of millions for good, but the next ambitious goal is to find an 
HIV cure before the year 2020. There are several approaches to an HIV cure ranging from shock and kill therapy, immunotherapy, vaccine development to gene editing using zinc finger nucleases and the CRISPR/Cas9 system, but finding the best possible solution is a challenge. One of the biggest challenges around any HIV treatment is the ability of the virus to rapidly mutate and develop resistance. Many of the new approaches do not provide any valuable insights as to whether the virus has the potential to become resistant. As of now, none of these functional cures have reached late-stage clinical trials, and the aim of finding an HIV cure until 2020 seems far-fetched. However, 2020 will likely be marked as an important milestone as the first late-stage trials will be executed. If successful, it could bring the approval of the first functional HIV cure in ten years.

There are two gene therapies undergoing human trialsone is to destroy the CCR5 receptor of the immune cells of people infected with HIV and the other therapy includes the CRISPR technology which is still under early trials. This mutation does not necessarily protect the person against all types of HIV. It was found that in one of the patients who had received the bone marrow treatment, it was found to have the CXCR4-tropic form. It uses a different type of receptor to enter and infect the cells. It was, however, not known whether this virus was acquired after the treatment or if some patients do contract a small amount of CXCR4-tropic virus that starts to multiply when other types are not present.

HIV research continues on many fronts that could provide the same results and only some of which rely on the CCR5 delta 32 mutation, which should be explored extensively. There are many strategies which are in the early stages of development. Scientific process can be slow but if done correctly, advances can be made to find a scalable, cost-effective cure for everyone.

Acknowledgments The authors listed in this paper wish to express their appreciation to the RSST trust Bangalore for their continuous support and encouragement.

Authors Contribution All authors have contributed equally with their valuable comments which made the manuscript to this form.

Funding There was no funding provided for the above research and preparation of the manuscript.

\section{Compliance with Ethical Standards}

Conflict of interest The authors declare that they have no conflict of interest.

Research Involving Human Participants and/or Animals All the authors listed hereby confirmed that in the above research, there were no human participants and/or animals involved in any kind of determination, evaluation or research studies.
Informed Consent There is also final confirmation given by all the listed authors for the submission of manuscript in its actual state. The authors listed above also confirm that the above-mentioned manuscript is in its original state and the manuscript is neither submitted anywhere nor in the submission process in any other journals. In addition, all the authors have solely contributed their original work in the preparation of this manuscript. If the copying or similarity have been found, then in all situations the listed authors are solely responsible.

\section{References}

1. Sepkowitz KA (2001) AIDS-the first 20 years. N Engl J Med 344(23):1764-1772. https://doi.org/10.1056/NEJM2001060734 42306

2. Alimonti JB, Ball TB, Fowke KR (2003) Mechanisms of CD4+ $\mathrm{T}$ lymphocyte cell death in human immunodeficiency virus infection and AIDS. J General Virol 84(Pt 7):1649-1661. https://doi.org/10.1099/vir.0.19110-0

3. Smith JA, Daniel R (2006) Following the path of the virus: the exploitation of host DNA repair mechanisms by retroviruses. ACS Chem Biol 1(4):217-226. https://doi.org/10.1021/cb600 $131 \mathrm{q}$

4. Gilbert PB, McKeague IW, Eisen G, Mullins C, Guéye-NDiaye A, Mboup S, Kanki PJ (2003) Comparison of HIV-1 and HIV-2 infectivity from a prospective cohort study in Senegal. Stat Med 22(4):573-593. https://doi.org/10.1002/sim.1342

5. Thumbi Ndung'u (2017). Four big insights into HIV/AIDS that provide hope of finding a vaccine. The Conversation. https://theconversation.com/four-big-insights-into-hiv-aids-thatprovide-hope-of-finding-a-vaccine-86736. Accessed 18 Aug 2019.

6. Murphy PM (2001) Viral exploitation and subversion of the immune system through chemokine mimicry. Nat Immunol 2(2):116-122. https://doi.org/10.1038/84214

7. Alkhatib G (2009) The biology of CCR5 and CXCR4. CurrOpin HIV AIDS 4(2):96-103. https://doi.org/10.1097/COH.0b013e3 28324bbec

8. Andrea Rubbert, Georg Behrens, Mario Ostrowski (2011). Pathogenesis of HIV-1 Infection. Published in hivbook.com. https://www.hivbook.com/2011/10/28/3-pathogenesis-of-hiv-1infection/. Accessed 18 Aug 2019.

9. Zidovudine. The American Society of Health-System Pharmacists. Archived from the original on December 21, 2016. Retrieved November 28, 2016. https://www.drugs.com/mono graph/zidovudine.html. Accessed 19 August 2019.

10. Yarchoan R, Mitsuya H, Myers C, Broder S (1989) Clinical pharmacology of 3'-azido-2',3'-dideoxythymidine (zidovudine) and related dideoxynucleosides. N Engl J Med 321(11):726-738. https://doi.org/10.1056/NEJM198909143211106

11. Zidovudine. U S National Library of Medicine, NCBI. PubChem. Accessed August 18 2019. https://pubchem.ncbi.nlm.nih.gov/ compound/Zidovudine.

12. Velasco-Velázquez M, Jiao X, De La Fuente M, Pestell TG, Ertel A, Lisanti MP, Pestell RG (2012) CCR5 antagonist blocks metastasis of basal breast cancer cells. Can Res 72(15): 3839-3850. https://doi.org/10.1158/0008-5472.CAN-11-3917

13. Sicoli D, Jiao X, Ju X, Velasco-Velazquez M, Ertel A, Addya S, Li Z, Andò S, Fatatis A, Paudyal B, Cristofanilli M, Thakur ML, Lisanti MP, Pestell RG (2014) CCR5 receptor antagonists block metastasis to bone of $\mathrm{v}-\mathrm{Src}$ oncogene-transformed metastatic prostate cancer cell lines. Can Res 74(23):7103-7114. https://doi.org/10.1158/0008-5472.CAN-14-0612 
14. Barmania F, Pepper MS (2013) C-C chemokine receptor type five (CCR5): An emerging target for the control of HIV infection. Appl Transl Genom 2:3-16. https://doi.org/10.1016/j.atg.2013. 05.004 (PMID: 27942440)

15. CCR5 gene. Genetics Home Reference. U. S. National Library of Medicine. https://ghr.nlm.nih.gov/gene/CCR5. Accessed 18 Aug 2019

16. Team SSARP (2019). CCR5-delta 32: The rare mutation that could help stop HIV. Project UPSC- wordpress.com. https://projectupsc.wordpress.com/2019/03/09/ccr5-delta-32-therare-mutation-that-could-help-stop-hiv/. Accessed 18 Aug 2019

17. Health Team (2019). What Is an Allogeneic Stem Cell Transplant? Wellness Destination India. https://www.wellnessdestin ationindia.com/allogeneic-bone-marrow-or-stem-cell-transplantcost-in-india/. Accessed 18 Aug 2019

18. Sankaranantham M (2019) HIV-is a cure possible? Indian J Sex Transmit Diseas AIDS 40(1):1-5. https://doi.org/10.4103/ ijstd.IJSTD_112_15 (PMID: 31143852)

19 Ghosh D, Venkataramani P, Nandi S (2019) CRISPR-Cas9 a boon or bane: the bumpy road ahead to cancer therapeutics. Cancer Cell Int. https://doi.org/10.1186/s12935-019-0726-0

20. Brown TR (2015) I am the Berlin patient: a personal reflection. AIDS Res Hum Retroviruses 31(1):2-3. https://doi.org/10.1089/ AID.2014.0224 (PMID: 25328084)

21. CROI 2017: Timothy Brown, The Berlin Patient, Celebrates A Decade Cured of HIV (2017). VI Western Europe and Central Asia AIDS Conference, Moscow, Russia. http://en.eecaac2018. org/world/croi-2017-timothy-brown-the-berlin-patient-celebrates -a-decade-cured-of-hiv/. Accessed 18 Aug 2019

22. Leila Haghighat, Amrit K. Kamboj (2019). The 'London Patient' goes into HIV remission: Here's what that means for HIV treatment. abc News. https://abcnews.go.com/Health/london- patient-hiv-remission-means-hiv-treatment/story?id=61564150. Accessed 19 Aug 2019

23. Jon Cohen (2020). Second 'cured' HIV patient goes public. Science Magazine. https://www.sciencemag.org/news/2020/03/ second-cured-hiv-patient-goes-public. Accessed 5 Jan 2021

24. Vincent Racaniello (2019). The London Patient. Virology blog. http://www.virology.ws/2019/03/13/the-london-patient/. Accessed 19 Aug 2019

25. The Basics of HIV Prevention (2019). AIDS info. U. S. Department of Health and Human Services. https://aidsinfo.nih. gov/understanding-hiv-aids/fact-sheets/20/48/the-basics-of-hivprevention. Accessed 20 Aug 2019

26. Rajendran S, Gupta PK, Hiremath L, Kumar SN, Srivastava AK (2019) An update on effective patient monitoring and diagnosis of diseases in the current scenario. Recent advances in computational intelligence. vol 823, pp 199-214. Springer, Berlin. https://doi.org/https://doi.org/10.1007/978-3-030-12500-4_11

27. Santoro MM, Perno CF. HIV-1 Genetic Variability and Clinical Implications. ISRN Microbiol. 2013;2013:481314. Published 2013 Jun 17. doi:https://doi.org/10.1155/2013/481314.ISBN 978-3-030-12500-4

28. Lemey P, Kosakovsky Pond SL, Drummond AJ et al (2007) Synonymous substitution rates predict HIV disease progression as a result of underlying replication dynamics. PLoS Comput Biol 3(2):e29. https://doi.org/10.1371/journal.pcbi.0030029

29. Tang MW, Shafer RW (2012) HIV-1 antiretroviral resistance: scientific principles and clinical applications. Drugs 72(9):e1e25. https://doi.org/10.2165/11633630-000000000-00000

Publisher's Note Springer Nature remains neutral with regard to jurisdictional claims in published maps and institutional affiliations. 